\title{
Amycolatopsis roodepoortensis sp. nov. and Amycolatopsis speibonae sp. nov.: antibiotic-producing actinobacteria isolated from South African soils
}

\author{
Gareth J Everest, Marilize le Roes-Hill ${ }^{1}$, Jeffrey Rohland ${ }^{1}$, Salomi Enslin and Paul R Meyers
}

Two novel members of the genus Amycolatopsis were isolated from soil samples collected in South Africa. Strains JS72 ${ }^{\top}$ and $\mathrm{M} 29^{\top}$ clustered in the same clade in the 16S-rRNA, gyrB-16S-rRNA and gyrB-recN gene trees. Both strains showed anti-mycobacterial activity. The oxyB P450 monooxygenase B gene required for the production of glycopeptide antibiotics was detected in both strains, while strain $\mathrm{JS}{ }^{\top}{ }^{\top}$ was also shown to contain the 3-amino-5-hydroxy-benzoic acid synthase gene, which is required for the production of the ansamycin class of antibiotics. Genetic distance values (based on the gyrB and recN genes) were calculated between strains $\mathrm{JS}_{2}{ }^{\top}$ and $\mathrm{M} 29^{\top}$ and their closest phylogenetic relatives. The values for strain $\mathrm{JS}^{\mathrm{S}}{ }^{\top}$ were all above the threshold values of 0.02 and 0.04 , respectively, that have been proposed to distinguish Amycolatopsis-type strains. The gyrB-based values for strain $\mathrm{M}^{2} \mathrm{~g}^{\mathrm{T}}$ were above the threshold for all but one strain; the recN-based values were all above the threshold. These data, along with DNA-DNA hybridization data, showed that strains $\mathrm{JS}^{\mathrm{S}}{ }^{\top}$ and $\mathrm{M}^{\mathrm{M}} \mathrm{9}^{\top}$ belong to distinct genomic species. The physiological, phylogenetic and genetic distance data support the description of strains JS72 ${ }^{\top}$ and $\mathrm{M}^{2} 9^{\top}$ as the type strains of novel species, for which the names Amycolatopsis speibonae sp. nov. (=DSM $46660^{\top}=\mathrm{NRRL}^{\top}$ B-24958 $\left.{ }^{\mathrm{T}}\right)$ and Amycolatopsis roodepoortensis sp. nov. ( $=$ DSM $46661^{\mathrm{T}}=$ NRRL B-24959 $\left.{ }^{\mathrm{T}}\right)$ are proposed, respectively.

The Journal of Antibiotics (2014) 67, 813-818; doi:10.1038/ja.2014.79; published online 25 June 2014

\section{INTRODUCTION}

The genus Amycolatopsis ${ }^{1}$ belongs to the family Pseudonocardiaceae and contains nocardioform actinomycetes that lack mycolic acids and contain meso-diaminopimelic acid, arabinose and galactose in their cell wall peptidoglycan. The genus is known for its antibioticproducing strains, producing among others the ansamycin-type antibiotic rifamycin (by Amycolatopsis mediterranei and Amycolatopsis rifamycinica $)^{2-4}$ and the glycopeptide antibiotic vancomycin (by Amycolatopsis orientalis). ${ }^{4}$ Of the antibiotics produced by this genus, the ansamycin and glycopeptide classes are the most important to medicine. With the continued emergence of antibiotic resistance in bacterial pathogens, there is always a need for the discovery of new antibiotics to combat the resistance. As several members of the genus Amycolatopsis produce antibiotics, the genus provides an ideal source of strains to screen for such novel compounds. With the descriptions of Amycolatopsis cihanbeyliensis ${ }^{5}$ and Amycolatopsis jiangsuensis, ${ }^{6}$ the number of members in the genus with validly published names has risen to $62 .^{7}$ Recent advances in the taxonomy of the genus involve using phylogenetic and genetic distance analyses based on the $\operatorname{grr} B$ and $\operatorname{recN}$ genes for distinguishing between genomic species. ${ }^{89}$ Here we describe the characterization of two novel members of the genus isolated from soil samples collected from two locations in South Africa.

\section{MATERIALS AND METHODS}

Isolation

Strain $\mathrm{M} 29^{\mathrm{T}}$ was isolated from a soil sample collected from a suburban garden in Roodepoort, Gauteng Province, South Africa, and strain $J S 72^{\mathrm{T}}$ from soil collected on Table Mountain above the Upper Campus of the University of Cape Town, Cape Town, South Africa. The soil sample collected from Roodepoort was subjected to microwave pretreatment. One gram of soil was vortexed in 10-ml sterile distilled water for $1 \mathrm{~min}$. One milliliter of the suspension was transferred to a sterile glass Petri dish and exposed to microwave radiation ( $950 \mathrm{~W}$ output microwave oven on full power) for $20 \mathrm{~s}$. After the microwave treatment the suspension was allowed to cool, serially diluted in sterile distilled water, spread-plated onto Modified Czapek Solution (MC) agar ${ }^{10}$ and incubated at $30^{\circ} \mathrm{C}$ for 21 days. The Table Mountain soil was not subjected to any pretreatment. A soil suspension was prepared as mentioned above before being serially diluted and spread-plated onto Difco Middlebrook 7H9 agar (7H9; Becton, Dickinson, Sparks, MD, USA) containing $10 \mathrm{mmoll}^{-1}$ glucose (albumin-dextrose-catalase supplement omitted) and incubated at $30^{\circ} \mathrm{C}$ for 14 days. After subculturing, both strains were maintained on yeast extract-malt extract agar (International Streptomyces Project (ISP) medium 2). ${ }^{11}$ 


\section{Genomic and phylogenetic analyses}

Genomic DNA was extracted as previously described. ${ }^{12}$ The rapid identification of the isolates to the genus level was achieved by 16S-rRNA gene amplification and restriction endonuclease digestion, ${ }^{13}$ using single digestions with MboI (Sau3AI isoschizomer), VspI (AsnI isoschizomer), SphI, KpnI, HindIII, SalI and Psp1406I. The gyrB gene was amplified using the 7G-gyrB-F and GgyrB-R1, and GgyrB-F1 and 7G-gyrB-R primer combinations and the standard PCR conditions described by Everest and Meyers. ${ }^{8}$ The recN gene was amplified as described in Everest et al. ${ }^{9}$ Strains were screened for antibiotic biosynthetic genes involved in the production of ansamycin (Type I polyketide), glycopeptide and Type II (aromatic) polyketide antibiotics as per Wood et al. ${ }^{14}$ The PCR products were purified using an MSB Spin PCRapace kit (Invitek, Berlin, Germany) and sequenced. Sequence analysis, generation of concatenated gene sequences, genetic distance calculations and phylogenetic analyses were performed as detailed in Everest et al. ${ }^{15}$ DNA hybridization analysis was performed as a service by the BCCM/LMG culture collection as described in Everest et al., ${ }^{15}$ with hybridizations being performed at $51^{\circ} \mathrm{C}$. Data are displayed as an average DNA-DNA hybridization value with the difference between the means of the reciprocal values given in parentheses.

\section{Antibacterial analysis}

Antimicrobial testing was performed using the standard agar overlay method as detailed in Wood et al. ${ }^{14}$ Strains were stab inoculated onto agar plates of MC, 7H9, ISP 2, Hacène's medium, ${ }^{16}$ a medium for the enhancement of antibiotic-production by Nocardia strains ${ }^{17}$ and a medium for the enhancement of antibiotic production by Streptosporangium strains ${ }^{17}$ and incubated at $30^{\circ} \mathrm{C}$ for $7-10$ days. Tests for growth inhibition were performed against Escherichia coli ATCC 25922, Enterococcus faecalis (vancomycin sensitive), Enterococcus faecium (clinical isolate; VanA), Enterococcus phoeniculicola JLB-1 $1^{\mathrm{T}}$, Mycobacterium aurum $\mathrm{A}+$ and Staphylococcus aureus ATCC 25923.

In addition, extractions were performed with equal volumes of organic solvents (chloroform, ethyl acetate and methanol) on the cell mass and culture filtrate fractions of 100-ml ISP 2 liquid cultures grown for 7 days at $30^{\circ} \mathrm{C}$ with shaking. These extracts were concentrated 50 times and tested for activity using spot test bioautography ${ }^{18}$ against Bacillus subtilis var ING, E. faecium (clinical isolate; VanA), E. coli ATCC 25922, M. aurum A +, Mycobacterium bovis strain BCG (Tokyo), Mycobacterium smegmatis LR222, Mycobacterium tuberculosis $\mathrm{H}_{37 \mathrm{Rv}^{\mathrm{T}}}$ (= ATCC 27294 ${ }^{\mathrm{T}}$ ) and Pseudomonas aeruginosa ATCC 27853.

\section{Characterization}

Morphological, physiological and chemotaxonomic characterization (diagnostic diamino acid in the peptidoglycan, cell wall sugars and polar lipids) were performed as detailed in Everest et al. ${ }^{15}$ The analysis of respiratory quinones was carried out by the Identification Service of the Deutsche Sammlung von Mikroorganismen und Zellkulturen (DSMZ, Braunschweig, Germany) on freeze-dried cells of cultures grown in ISP 2 broth at $30^{\circ} \mathrm{C}$ for 3 days with moderate shaking. Fatty acid analyses were performed as a service by the BCCM/LMG Culture Collection, as per the recommendations of the commercial identification system MIDI (Microbial Identification System, Newark, DE, USA; MIDI Sherlock version 3.10; database TSBA 50 (rev 5.0)), on cells grown at $28^{\circ} \mathrm{C}$ for 3 days on Tryptic Soy Agar (BBL 11768).

\section{RESULTS AND DISCUSSION}

Strains $\mathrm{SS}_{2} 2^{\mathrm{T}}$ and $\mathrm{M} 29^{\mathrm{T}}$ were determined to belong to one of the genera Amycolatopsis, Pseudonocardia or Saccharopolyspora, based on the analysis of the 16S-rRNA gene restriction fragment patterns. ${ }^{13}$ BLASTN analysis, ${ }^{19}$ based on $1410 \mathrm{bp}$ of $16 \mathrm{~S}$-rRNA gene sequence for $\mathrm{JS}_{2} 2^{\mathrm{T}}$ and $1411 \mathrm{bp}$ for $\mathrm{M} 29^{\mathrm{T}}$, showed that both strains belong to the genus Amycolatopsis. The closest relatives of strain $\mathrm{JS}_{2} 2^{\mathrm{T}}$ were determined to be Amycolatopsis thailandensis CMU-PLA07 ${ }^{\mathrm{T}}$ (99.15\% 16S-rRNA gene sequence similarity as per BLAST), Amycolatopsis coloradensis DSM $44225^{\mathrm{T}}$ (99.08\%) and Amycolatopsis umgeniensis $\mathrm{UM}^{6} 6^{\mathrm{T}}$ (99.07\%). The closest relatives of strain $\mathrm{M} 29^{\mathrm{T}}$ were determined to be Amycolatopsis decaplanina DSM $44594^{\mathrm{T}}$ (99.22\%),
Amycolatopsis regifaucium $\mathrm{GY} 080^{\mathrm{T}}$ (99.01\%) and Amycolatopsis keratiniphila subsp. nogabecina DSM 44586 ${ }^{\mathrm{T}}$ (99.01\%). Analysis of the 16S-rRNA gene sequences using EzTaxon- $\mathrm{e}^{20}$ revealed Amycolatopsis lurida DSM $43134^{\mathrm{T}}$ (99.26\% 16S-rRNA gene sequence similarity) and Amycolatopsis keratiniphila subsp keratiniphila DSM $44409^{\mathrm{T}}(99.12 \%)$ as additional close relatives of strains $\mathrm{JS72}^{\mathrm{T}}$ and $\mathrm{M} 29^{\mathrm{T}}$, with $99.48 \%$ and $99.05 \%$ similarity, respectively.

The construction of a 16S-rRNA gene maximum-likelihood phylogenetic tree ${ }^{21}$ showed that strain $\mathrm{M} 29^{\mathrm{T}}$ grouped with A. regifaucium $\mathrm{GY} 080^{\mathrm{T}}$ and strain $\mathrm{JS}^{\mathrm{T}}{ }^{\mathrm{T}}$ with $A$. keratiniphila subsp keratiniphila DSM $44409^{\mathrm{T}}$ (with low bootstrap support), within cluster A as defined by Everest and Meyers ${ }^{8}$ (Figure 1). Strains $\mathrm{JS}_{2} 2^{\mathrm{T}}$ and $\mathrm{M} 29^{\mathrm{T}}$ share $99.15 \%$ 16S-rRNA gene sequence similarity.

A phylogenetic tree based on the concatenated gyrB-16S-rRNA gene sequences (Supplementary Figure 1) was also constructed and supported the association depicted in the 16S-rRNA gene phylogenetic tree for strain $\mathrm{M} 29^{\mathrm{T}}$, with some minor rearrangements of the branches, but improved bootstrap support. The position of strain $\mathrm{JS72}^{\mathrm{T}}$, however, changed and it now formed an association with A. umgeniensis, but with very low bootstrap support (Supplementary Figure 1). Strain $J S 72^{\mathrm{T}}$ was found to be most closely related to Amycolatopsis alba in the gyrB-recN concatenated gene phylogenetic tree (Figure 2 and Supplementary Figure 2), but the bootstrap support for this association was weak (51\%). The 16S-rRNA gene sequence similarity between strain $\mathrm{JS}^{\mathrm{T}} 2^{\mathrm{T}}$ and the type strain of $A$. alba is $98.72 \%$. The gyrB-recN concatenated gene tree showed that strain $\mathrm{M} 29^{\mathrm{T}}$ clustered similarly to the other trees, but formed a close association with $A$. lurida with low (66\%) bootstrap support (Figure 2).

The number of nodes with bootstrap values $>70 \%$ (that is, moderate support for the depicted tree topology) in the clade containing strains $\mathrm{JS}_{2} 2^{\mathrm{T}}$ and $\mathrm{M} 29^{\mathrm{T}}$ was two in the $16 \mathrm{~S}$-rRNA gene tree (Figure 1), six in the gyrB-16S-rRNA gene tree (Supplementary Figure 1) and six in the $g y r B-r e c N$ gene tree (Figure 2). Furthermore, the bootstrap values for the associations in Supplementary Figure 1 and Figure 2 were much higher than those in Figure 1 (the majority of which were $<40 \%$; data not shown).

Genetic distance values, based on the gyrB gene (1290 bp), were calculated between strains $\mathrm{JS} 72^{\mathrm{T}}, \mathrm{M} 29^{\mathrm{T}}$ and all the type strains of Amycolatopsis species for which gyrB sequences are available (Supplementary Table 1), to assess whether these strains were likely to represent new species. ${ }^{8}$ The values for strain $\mathrm{JS} 2^{\mathrm{T}}$ ranged from 0.026 to $0.213\left(0.036-0.439\right.$ based on the 315 bp variable region $\left.{ }^{8}\right)$ and for strain $\mathrm{M} 29^{\mathrm{T}}$ they ranged from 0.013 to 0.210 (0.018-0.428 based on the 315-bp variable region). The gyrB gene-based genetic distance values between strain $J S 72^{\mathrm{T}}$ and the type strains of 16S-rRNA gene cluster A (Figure 1) were all above the 0.02 threshold proposed to distinguish genomic species ${ }^{8}(0.026-0.055 ; 0.036-0.116$ based on the 315-bp variable region). The values between strain $\mathrm{M} 29^{\mathrm{T}}$ and A. keratiniphila subsp. keratiniphila, A. keratiniphila subsp. nogabecina and A. lurida were $0.013,0.017$ and 0.019 (0.021, 0.021 and 0.018 based on the 315 -bp variable region). The values between strain $\mathrm{M} 29^{\mathrm{T}}$ and all the other members of 16S-rRNA gene cluster A were above the 0.02 threshold $(0.022-0.051 ; 0.028-0.100$ based on the 315 -bp variable region). These data show that strain $\mathrm{M} 29^{\mathrm{T}}$ is likely a distinct genomic species from all Amycolatopsis-type strains except A. lurida (based on the 315-bp variable region). Thus, further evidence is needed to prove that strain $\mathrm{M} 29^{\mathrm{T}}$ is a distinct species from A. lurida. The gyrB genetic distance between $\mathrm{JS}_{2} 2^{\mathrm{T}}$ and $\mathrm{M} 29^{\mathrm{T}}$ was 0.046 ( 0.081 based on 315 -bp variable region), above the 0.02 threshold, which indicates they are likely separate species. ${ }^{8}$ 


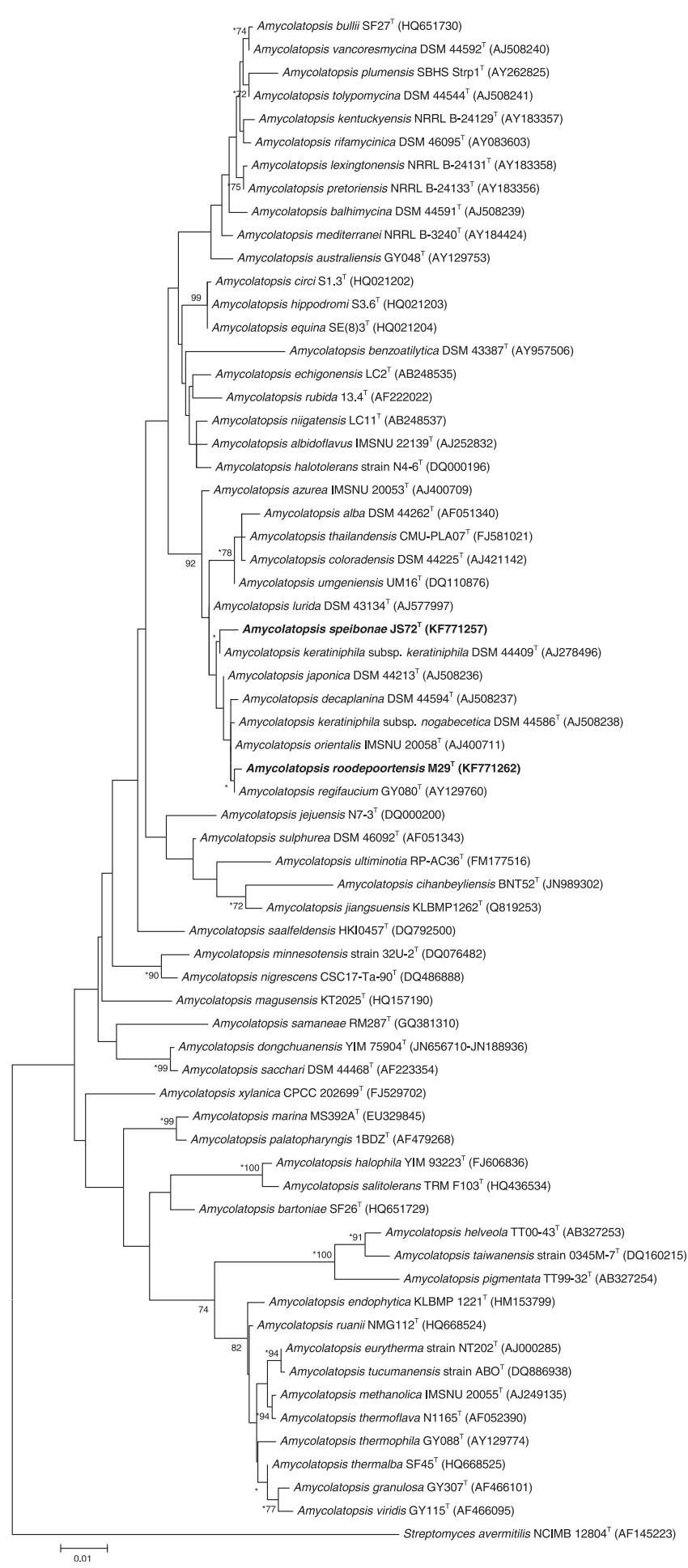

Figure 1 16S-rRNA gene phylogenetic tree showing the positions of strains $\mathrm{JS} 2^{\top}$ and M29 ${ }^{\top}$ within cluster A of the genus Amycolatopsis. The tree was constructed using the maximum likelihood method based on $1353 \mathrm{bp}$ of common sequence. The percentage bootstrap values of 1000 replications are shown at each node (only values above $70 \%$ are shown), with asterisks $\left({ }^{*}\right)$ indicating the clades that were also formed in the trees constructed using the neighbor joining 28 and maximum parsimony ${ }^{29}$ algorithms. Accession numbers are indicated in parenthesis after the strain numbers. The scale bar indicates 1 nucleotide substitution per 100 nucleotides.

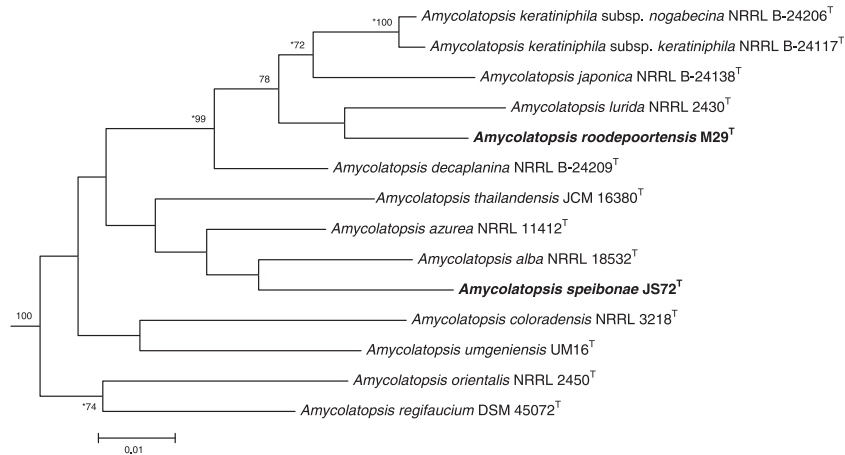

Figure 2 Subtree of the phylogenetic tree based on the concatenated gyrBrecN gene sequences showing the relationships of strains $\mathrm{JS}^{\top} 2^{\top}$ and $\mathrm{M} 29^{\top}$ to closely related type strains. The tree forms part of a full maximumlikelihood tree, constructed based on $2520 \mathrm{bp}$ of sequence for the 40 members of the genus for which gyrB and $r e c N$ gene sequences are available (Supplementary Figure 2). The percentage bootstrap values of 1000 replications are shown at each node (only values above $70 \%$ are shown), with asterisks $\left(^{*}\right)$ indicating the clades that were also formed in the trees constructed using the neighbor joining and maximum parsimony algorithms. The strain numbers of the strains from which the gyrB and recN gene sequences were obtained are indicated. The scale bar indicates 1 nucleotide substitution per 100 nucleotides.

The $r e c N$ gene-based genetic distance values (1231 bp) were calculated between strains $\mathrm{JS} 72^{\mathrm{T}}, \mathrm{M} 29^{\mathrm{T}}$ and all type strains for which $r e c N$ gene sequences are available (Supplementary Table 1). For strain $\mathrm{JS}_{2}{ }^{\mathrm{T}}$ these genetic distances ranged from 0.056 to 0.317 (with the genetic distances against members of its 16S-rRNA gene cluster ranging from 0.056 to 0.095 ) and for strain $\mathrm{M} 29^{\mathrm{T}}$ the values ranged from 0.055 to 0.318 (with the genetic distances against members of 16S-rRNA gene cluster A ranging from 0.055 to 0.107 ). The $r e c N$ genetic distance between strains $\mathrm{JS} 72^{\mathrm{T}}$ and $\mathrm{M} 29^{\mathrm{T}}$ was 0.095 . All these values are above the proposed 0.04 threshold to distinguish novel species in the genus. ${ }^{9}$ These data further suggest that strains $\mathrm{JS} 2^{\mathrm{T}}$ and $\mathrm{M} 29^{\mathrm{T}}$ are distinct species from all type strains of the genus Amycolatopsis. All gyrB- and recN-gene-based genetic distance values are presented in Supplementary Figures 3-5.

DNA-DNA hybridization experiments were performed between strains $J 572^{\mathrm{T}}$ and $\mathrm{M} 29^{\mathrm{T}}$ and their closest relatives based on 16S-rRNA gene sequence similarities. The results show that strain $J S 72^{\mathrm{T}}$ shared $50(15) \%$ DNA relatedness to $A$. thailandensis $\mathrm{JCM} 16380^{\mathrm{T}}$ and $48(5) \%$ to A. lurida NRRL $2430^{\mathrm{T}}$. Strain M29 $9^{\mathrm{T}}$ shared $29(25) \%$ to A. lurida NRRL $2430^{\mathrm{T}}, 26(25) \%$ to A. keratiniphila subsp. nogabecina NRRL B-24256 ${ }^{\mathrm{T}}$ and $22(8) \%$ to A. decaplanina NRRL B-24209'. Strains $\mathrm{JS}_{2}{ }^{\mathrm{T}}$ and $\mathrm{M} 29^{\mathrm{T}}$ shared $25(5) \%$ DNA relatedness. This proves that both strains $\mathrm{JS}_{2} 2^{\mathrm{T}}$ and $\mathrm{M} 29^{\mathrm{T}}$ are distinct genomic species. ${ }^{22}$

Screening for antibiotic biosynthetic genes revealed the presence of the $\mathrm{P} 450$ monooxygenase $\mathrm{B}(o x y B)$ gene, required for the production of glycopeptide antibiotics, in both strains $\mathrm{JS}^{2} 2^{\mathrm{T}}$ (GenBank accession number: KF771261) and M29 $9^{\mathrm{T}}$ (KF771265). Strain $\mathrm{JS}^{\mathrm{T}}{ }^{\mathrm{T}}$ was also shown to contain the 3-amino-5-hydroxy-benzoic acid synthase gene (KF771260), required for the production of ansamycin antibiotics.

Overlay experiments showed that strain $\mathrm{JS}^{\mathrm{T}} \mathrm{T}^{\mathrm{T}}$ exhibited antibacterial activity against $M$. aurum A+, E. faecalis (vancomycin sensitive), E. phoeniculicola JLB- $1^{\mathrm{T}}$ and S. aureus ATCC 25923, but showed no activity against E. coli ATCC 25922 and E. faecium VanA (vancomycin resistant). Strain $\mathrm{M} 29^{\mathrm{T}}$ showed activity against M. aurum A+, but no activity against E. coli ATCC 25922 and E. faecium VanA. Combined solvent extracts of the broth culture of 
strain $\mathrm{M} 29^{\mathrm{T}}$ showed activity against $B$. subtilis var ING, $M$. bovis BCG (Tokyo), M. aurum A+, M. smegmatis LR222, M. tuberculosis $\mathrm{H}_{37 \mathrm{Rv}^{\mathrm{T}}}$ and $P$. aeruginosa ATCC 27853, but no activity against E. coli ATCC 25922 and E. faecium VanA.

Both strains $\mathrm{JS} 72^{\mathrm{T}}$ and $\mathrm{M} 29^{\mathrm{T}}$ grouped in 16S-rRNA gene cluster A of Everest and Meyers, ${ }^{8}$ which contains most of the glycopeptideproducing Amycolatopsis type strains. ${ }^{23}$ The presence of the genes for glycopeptide production in these strains and their inability to inhibit the vancomycin-resistant $E$. faecium VanA strain suggest that these strains produce a glycopeptide-type antibiotic. Further support for this is lent by the fact that strain $\mathrm{JS}^{\mathrm{T}}{ }^{\mathrm{T}}$ shows activity against a vancomycin-sensitive E. faecalis strain.

The results of the phenotypic characterization of strains $J S 72^{\mathrm{T}}$ and $\mathrm{M} 29^{\mathrm{T}}$ are presented in Table 1 and the species descriptions. These data showed that the strains are phenotypically distinct from their closesttype strain relatives. The chemotaxonomic characteristics of the strains are presented in the species description and are consistent with membership of the genus Amycolatopsis. ${ }^{1,24-26}$

\section{Description of Amycolatopsis speibonae sp. nov.}

Amycolatopsis speibonae (spei.bo'nae. L. n. spes -ei hope; L. adj. bonus good; N.L. fem. adj. speibonae of good hope, to indicate Cape Town, the Cape of Good Hope, South Africa, the source of the soil from which the type strain was isolated).

Gram positive. Colonies appear convoluted with raised centers on most media. Vegetative mycelium appears cream-brown in color, fragmenting into short rod-shaped elements in both liquid and agar cultures. Aerial mycelium appears white on ISP 4. No diffusible

Table 1 Phenotypic differences between strains $\mathrm{M}^{\top} 9^{\top}, \mathrm{JS72}^{\top}$ and closely related Amycolatopsis-type strains

\begin{tabular}{|c|c|c|c|c|c|c|c|c|c|c|c|c|c|c|}
\hline Test & $J S 72^{T}$ & $M 29^{T}$ & 1 & 2 & 3 & 4 & 5 & 6 & 7 & 8 & 9 & 10 & 11 & 12 \\
\hline \multicolumn{15}{|l|}{ Color of } \\
\hline Spore mass (on ISP 4) & Wh & $\mathrm{Cr}$ & Wh & Wh & Wh & Wh & Wh & Wh & $\mathrm{Cr}$ & Cr-Wh & $\mathrm{Cr}-\mathrm{Wh}$ & $\mathrm{Cr}$ & Wh & Wh \\
\hline Diffusible pigments & - & - & - & - & Yel & - & - & - & - & - & - & - & - & - \\
\hline $\mathrm{H}_{2} \mathrm{~S}$ production & - & + & + & - & + & + & + & + & + & + & + & + & + & $+\mathrm{w}$ \\
\hline Nitrate reduction & + & - & - & + & - & + & - & + & + & - & + & - & - & + \\
\hline \multicolumn{15}{|l|}{ Degradation of } \\
\hline Allantoin & $+w$ & - & $+w$ & - & - & - & - & - & - & - & - & - & - & + \\
\hline Guanine & - & - & - & - & - & - & - & - & - & - & - & - & - & + \\
\hline Urea & + & + & - & - & + & + & + & + & + & + & - & - & + & + \\
\hline Xanthine & - & + & $+w$ & + & $+w$ & + & + & $+w$ & - & + & $+w$ & + & + & + \\
\hline Xylan & - & $+w$ & - & - & - & - & - & - & - & - & $+w$ & $+w$ & - & - \\
\hline \multicolumn{15}{|l|}{ Growth at } \\
\hline pH 4.3 & + & + & - & - & $+w$ & ++ & - & + & + & $+\mathrm{w}$ & - & - & ++ & + \\
\hline $\mathrm{pH} 10$ & ++ & ++ & - & - & + & ++ & $+w$ & ++ & ++ & + & $+w$ & - & ++ & + \\
\hline $37^{\circ} \mathrm{C}$ & - & + & - & $+w$ & + & ++ & + & + & ++ & + & ++ & ++ & + & - \\
\hline \multicolumn{15}{|l|}{ Growth in the presence of } \\
\hline $2 \%(w / v) \mathrm{NaCl}$ & ++ & ++ & - & + & + & ++ & $+w$ & ++ & ++ & + & - & + & + & + \\
\hline $4 \%(\mathrm{w} / \mathrm{v}) \mathrm{NaCl}$ & + & + & - & + & + & ++ & $+\mathrm{w}$ & + & + & $+w$ & - & - & + & + \\
\hline $7 \%(w / v) \mathrm{NaCl}$ & - & $+w$ & - & + & $+w$ & $+w$ & - & $+w$ & - & - & - & - & $+w$ & + \\
\hline \multicolumn{15}{|c|}{ Utilization as sole carbon source } \\
\hline Adonitol & + & ++ & ++ & + & - & - & ++ & $+\mathrm{w}$ & + & + & ++ & - & - & ++ \\
\hline $\mathrm{L}(+)$-Arabinose & + & ++ & - & ++ & - & ++ & + & + & ++ & + & + & + & - & + \\
\hline Lactose & $+\mathrm{w}$ & + & + & + & - & ++ & + & + & ++ & $+\mathrm{w}$ & + & $+w$ & ++ & + \\
\hline$D(+)$-Melibiose & $+w$ & - & + & $+w$ & - & ++ & ++ & + & - & - & $+w$ & - & $+w$ & ++ \\
\hline Raffinose & $+w$ & - & $+w$ & $+w$ & - & $+w$ & + & $+w$ & - & - & $+w$ & - & $+w$ & + \\
\hline $\mathrm{L}(+)$-Rhamnose & - & - & - & - & - & - & - & - & - & - & ++ & - & - & - \\
\hline Sodium citrate & $+w$ & $+w$ & $+w$ & $+w$ & $+w$ & $+w$ & $+w$ & $+w$ & $+w$ & $+w$ & $+w$ & $+w$ & - & + \\
\hline Sucrose & - & $+w$ & - & $+w$ & - & $+w$ & - & $+w$ & $+w$ & - & - & $+w$ & $+w$ & - \\
\hline \multicolumn{15}{|c|}{ Utilization of sole nitrogen source } \\
\hline DL- $\alpha$-amino-n-butyric acid & + & + & + & $+w$ & - & $+w$ & + & $+w$ & $+w$ & $+w$ & $+w$ & $+w$ & + & + \\
\hline L-Cysteine & $+w$ & $+w$ & $+w$ & $+w$ & - & $+w$ & $+w$ & $+w$ & $+w$ & $+w$ & $+w$ & $+w$ & $+w$ & + \\
\hline L-4-Hydroxyproline & $+w$ & $+w$ & $+w$ & $+w$ & - & $+w$ & ++ & $+w$ & + & - & $+w$ & $+w$ & + & + \\
\hline L-Methionine & - & $+\mathrm{w}$ & $+w$ & - & - & $+w$ & $+w$ & $+w$ & $+w$ & - & $+w$ & - & $+\mathrm{w}$ & $+\mathrm{w}$ \\
\hline L-Phenylalanine & $+w$ & + & + & $+w$ & - & $+w$ & + & ++ & + & $+w$ & + & w & + & + \\
\hline L-Threonine & + & $+w$ & $+w$ & + & - & $+w$ & $+w$ & + & ++ & $+w$ & + & $+\mathrm{w}$ & $+w$ & ++ \\
\hline L-Valine & $+w$ & + & + & + & - & $+w$ & + & + & + & $+w$ & + & $+w$ & $+w$ & ++ \\
\hline
\end{tabular}

Reference strains: 1 , A. alba NRRL $18532^{\top} ; 2$, A. azurea NRRL $11412^{\top} ; 3$, A. coloradensis NRRL $3218^{\top} ; 4$, A. decaplanina NRRL B-24209'; 5, A. japonica NRRL B-24138'; 6 , A. keratiniphila

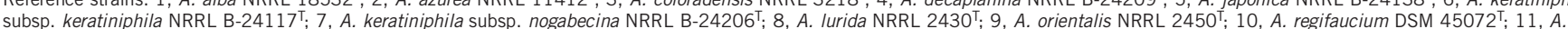
thailandensis JCM $16380^{\top}$; 12, A. umgeniensis UM16 . All data were determined in this study. Symbols: ++, strong positive; +, positive; + w, weakly positive; -, negative; Cr, cream; Wh, thailandensis JCM 
pigments are produced. Melanin is not produced on peptone-yeast extract-iron agar (ISP 6) or tyrosine agar (ISP 7). Grows at $30^{\circ} \mathrm{C}$, but not at $37^{\circ} \mathrm{C}$. Grows at $\mathrm{pH} 4.3,7$ and 10 as well as in the presence of up to $4 \%(\mathrm{w} / \mathrm{v}) \mathrm{NaCl}$, but not in the presence of $7 \%(\mathrm{w} / \mathrm{v}) \mathrm{NaCl}$. Catalase positive. Oxidase negative. Nitrate is reduced to nitrite. Does not produce $\mathrm{H}_{2} \mathrm{~S}$. Starch is not hydrolyzed. Casein, gelatin, hypoxanthine, Tween 80, L-tyrosine and urea are degraded. Allantoin is weakly degraded. Adenine, guanine, xanthine and xylan are not degraded. Utilizes adonitol, $\mathrm{L}(+)$-arabinose, $\mathrm{D}(+)$-cellobiose, $\mathrm{D}(-)$-fructose, $\mathrm{D}(+)$ )-glucose, meso-inositol, $\mathrm{D}(-)$-mannitol, $\mathrm{D}(+)$ mannose and $\mathrm{D}(+)$-xylose as sole carbon sources. Weakly utilizes raffinose, $\mathrm{D}(+)$-melibiose, $\alpha$-lactose, salicin, sodium acetate and sodium citrate. Unable to utilize inulin, $\mathrm{L}(+)$-rhamnose and sucrose as sole carbon sources. Utilizes DL- $\alpha$-amino-n-butyric acid, L-asparagine, L-histidine, potassium nitrate and L-threonine as sole nitrogen sources, with weak growth on L-arginine, L-cysteine, L-4-hydroxyproline, L-phenylalanine, L-serine and L-valine. Unable to utilize L-methionine as a sole nitrogen source. Contains a type IV cell wall (meso-diaminopimelic acid, arabinose and galactose in the cell wall). ${ }^{27}$ Mycolic acids are absent. The polar lipid profile includes diphosphatidylglycerol, phosphatidylethanolamine, phosphatidylmethylethanolamine, phosphatidylinositol, phosphatidylinositolmannoside, two unidentified phospholipids, two unidentified aminolipids, two unidentified glycolipids, an unidentified phosphoglycolipid and an unidentified aminophospholipid (Supplementary Figure 6). The predominant menaquinone is MK-9 $\left(\mathrm{H}_{4}\right)(85 \%)$, with minor amounts of MK- $8\left(\mathrm{H}_{4}\right)(11 \%)$. The major fatty acids of the type strain are $\mathrm{i}-\mathrm{C}_{15: 0}(17.36 \%), \mathrm{C}_{17: 1} \omega 8 c(16.93 \%), \mathrm{C}_{17: 0}(13.45 \%)$, ai- $\mathrm{C}_{15: 0}$ (11.14\%), $\mathrm{C}_{16: 1} \omega 7 c$ and/or iso- $\mathrm{C}_{15: 0} 2-\mathrm{OH}(9.44 \%)$ and $\mathrm{i}-\mathrm{C}_{16: 0}(9.7 \%)$, with minor amounts of $\mathrm{C}_{15: 1} \omega 6 c(7.42 \%), \mathrm{i}-\mathrm{C}_{14: 0}(6.5 \%)$, ai- $\mathrm{C}_{17: 0}$ (3.28\%), $\mathrm{C}_{17: 1} \omega 6 c$ (1.7\%), $\mathrm{C}_{13: 0}(1.54 \%)$ and $\mathrm{C}_{16: 0}(1.53 \%)$.

Antibacterial activity is exhibited against E. phoeniculicola JLB-1 ${ }^{\mathrm{T}}$, a vancomycin-sensitive Enterococcus sp., M. aurum A + and S. aureus ATCC 25923.

The type strain, $\mathrm{JS}^{\mathrm{T}}{ }^{\mathrm{T}}$ ( = DSM $46660^{\mathrm{T}}=\mathrm{NRRL} \mathrm{B}-24958^{\mathrm{T}}$ ), was isolated from soil from Table Mountain above the Upper Campus of the University of Cape Town, Cape Town, South Africa.

\section{Description of Amycolatopsis roodepoortensis sp. nov.}

Amycolatopsis roodepoortensis (roo.de.poort.en'sis. N.L. fem. adj. roodepoortensis, pertaining to Roodepoort, a suburb in Gauteng province of South Africa, the source of the soil from which the type strain was isolated).

Gram positive. Colonies appear convoluted with raised centers on most media. Vegetative mycelium appears cream-brown in color, fragmenting into short rod-shaped elements in both liquid and agar cultures. Aerial mycelium appears cream on ISP 4. No diffusible pigments are produced. Melanin is not produced on peptone-yeast extract-iron agar (ISP 6) or tyrosine agar (ISP 7). Grows at $30^{\circ} \mathrm{C}$ and at $37^{\circ} \mathrm{C}$. Grows at $\mathrm{pH} 4.3,7$ and 10 as well as in the presence of up to $7 \%(\mathrm{w} / \mathrm{v}) \mathrm{NaCl}$. Catalase positive. Oxidase negative. Nitrate is not reduced to nitrite. Produces $\mathrm{H}_{2} \mathrm{~S}$. Starch is not hydrolyzed. Casein, gelatin, hypoxanthine, Tween 80 , L-tyrosine, urea and xanthine are degraded. Xylan is weakly degraded. Adenine, allantoin and guanine are not degraded. Utilizes adonitol, $\mathrm{L}(+)$-arabinose, $\mathrm{D}(+)$-cellobiose, $\mathrm{D}(-)$-fructose, $\mathrm{D}(+)$-glucose, meso-inositol, lactose, $\mathrm{D}(-)$ mannitol, $\mathrm{D}(+)$-mannose, salicin and $\mathrm{D}(+)$-xylose as sole carbon sources. Weakly utilizes sodium acetate, sodium citrate and sucrose. Unable to utilize inulin, $\mathrm{D}(+)$-melibiose, raffinose and $\mathrm{L}(+)$ rhamnose as a sole carbon source. Utilizes DL- $\alpha$-amino-n-butyric acid, L-arginine, L-asparagine, L-histidine, L-serine, L-valine and
L-phenylalanine as sole nitrogen sources, with weak growth on L-cysteine, L-4-hydroxyproline, L-methionine, potassium nitrate and L-threonine. Contains a type IV cell wall (meso-diaminopimelic acid, arabinose and galactose in the cell wall). ${ }^{27}$ Mycolic acids are absent. The polar lipid profile includes diphosphatidylglycerol, phosphatidylethanolamine, phosphatidylmethylethanolamine, phosphatidylinositol, two unidentified phospholipids, an unidentified aminolipid, six unidentified glycolipids, an unidentified aminophospholipid, three unidentified aminoglycolipids and an unidentified phosphoglycolipid (Supplementary Figure 7). The predominant menaquinone is MK- $9\left(\mathrm{H}_{4}\right)(84 \%)$, with minor amounts of MK- $8\left(\mathrm{H}_{4}\right)(12 \%)$ and MK-9 $\left(\mathrm{H}_{2}\right)(3 \%)$. The major fatty acids of the type strain are $\mathrm{C}_{17: 1} \omega 8 c(22.99 \%), \mathrm{i}-\mathrm{C}_{16: 0}(22.55 \%), \mathrm{C}_{17: 0}(9.5 \%)$ and $\mathrm{C}_{17: 1} \omega 6 c(9 \%)$, with minor amounts of $\mathrm{C}_{16: 1} \omega 7 \mathrm{c}$ and/or iso- $\mathrm{C}_{15: 0} 2$ $\mathrm{OH}(7 \%), \quad \mathrm{i}-\mathrm{C}_{15: 0}(6.75 \%), \mathrm{C}_{15: 1} \omega 6 \mathrm{c}(6.72 \%), \quad \mathrm{i}-\mathrm{C}_{14: 0} \quad(6.44 \%)$, ai- $\mathrm{C}_{15: 0} \quad(1.99 \%), \quad \mathrm{C}_{16: 0} \quad(1.85 \%), \quad$ ai- $\mathrm{C}_{17: 0} \quad(1.81 \%), \quad \mathrm{C}_{15: 0} \quad 2-\mathrm{OH}$ $(1.2 \%)$, i- $\mathrm{C}_{17: 0}(0.76 \%), \mathrm{C}_{18: 1} \omega 9 \mathrm{c}(0.53 \%), \mathrm{C}_{13: 0}(0.44 \%)$ and $\mathrm{C}_{14: 0}$ $(0.38 \%)$. Antibacterial activity is exhibited against $B$. subtilis var ING, M. bovis BCG (Tokyo), M. aurum A+, M. smegmatis LR222, M. tuberculosis $\mathrm{H} 37 \mathrm{Rv}^{\mathrm{T}}$ and $P$. aeruginosa ATCC 27853 .

The type strain, M29 ${ }^{\mathrm{T}}$ (=DSM $\left.46661^{\mathrm{T}}=\mathrm{NRRL} \mathrm{B}-24959^{\mathrm{T}}\right)$, was isolated from soil from a suburban garden in Roodepoort, Gauteng Province, South Africa.

\section{ACKNOWLEDGEMENTS}

We thank Aidan Parte for assistance with naming the isolates. GJE held a Claude Leon Foundation Postdoctoral Fellowship. JR holds a National Research Foundation Innovation Postdoctoral Fellowship. This work was supported by research grants to PRM from the Medical Research Council of South Africa, the NRF (grant numbers: 2073133, 81014 and 85476) and the University Research Committee (University of Cape Town).

\section{ACCESSION NUMBERS}

The GenBank accession numbers for the 16S-rRNA, gyrB and recN gene sequences of strain $\mathrm{JS}^{\mathrm{T}}{ }^{\mathrm{T}}$ are KF771257, KF771258 and KF771259, respectively, and those for strain $\mathrm{M}^{2} 9^{\mathrm{T}}$ are KF771262, KF771263 and KF771264, respectively.

1 Lechevalier, M. P., Prauser, H., Labeda, D. P. \& Ruan, J. S. Two new genera of nocardioform actinomycetes: Amycolata gen. nov. and Amycolatopsis gen. nov. Int. J. Syst. Bacteriol. 36, 29-37 (1986).

2 Bala, S. et al. Reclassification of Amycolatopsis mediterranei DSM 46095 as Amycolatopsis rifamycinica sp. nov. Int. J. Syst. Evol. Microbiol. 54, 1145-1149 (2004).

3 Sensi, P., Greco, A. M. \& Ballotta, R. Rifomycin I. Isolation and properties of rifomycin B and rifomycin complex. Antibiot. Annu. 7, 262-270 (1959).

4 Wink, J. et al. Three new antibiotic producing species of the genus Amycolatopsis, Amycolatopsis balhimycina sp. nov., A. tolypomycina sp. nov., A. vancoresmycina sp. nov., and description of Amycolatopsis keratiniphila subsp. keratiniphila subsp. nov. and A. keratiniphila subsp. nogabecina subsp. nov. Syst. Appl. Microbiol. 26, 38-46 (2003).

5 Tatar, D., Sazak, A., Guven, K., Cetin, D. \& Sahin, N. Amycolatopsis cihanbeyliensis sp. nov., a halotolerant actinomycete isolated from a salt mine. Int. J. Syst. Evol. Microbiol. 63, 3739-3743 (2013).

6 Xing, K. et al. Amycolatopsis jiangsuensis sp. nov., a novel endophytic actinomycete isolated from a coastal plant in Jiangsu, China. Antonie van Leeuwenhoek 103, 433-439 (2013)

7 Parte, A. C. List of prokaryotic names with standing in nomenclature. http://www. bacterio.net/a/amycolatopsis.html. Accessed August 2013.

8 Everest, G. J. \& Meyers, P. R. The use of gyrB gene sequence analysis in the phylogeny of the genus Amycolatopsis. Antonie van Leeuwenhoek 95, 1-11 (2009).

9 Everest, G. J., Cook, A. E., Kirby, B. M. \& Meyers, P. R. Evaluation of the use of recN sequence analysis in the phylogeny of the genus Amycolatopsis. Antonie van Leeuwenhoek 100, 483-496 (2011).

10 Nonomura, H. \& Ohara, Y. Distribution of actinomycetes in soil. VIII. Green spore group of Microtetraspora, its preferential isolation and taxonomic characteristics. J. Ferment. Technol. 49, 1-7 (1971).

11 Shirling, E. B. \& Gottlieb, D. Methods for characterization of Streptomyces species. Int J. Syst. Bacteriol. 16, 313-340 (1966). 
12 Everest, G. J. \& Meyers, P. R. Kribbella hippodromi sp. nov., isolated from soil from a racecourse in South Africa. Int. J. Syst. Evol. Microbiol. 58, 443-446 (2008).

13 Cook, A. E. \& Meyers, P. R. Rapid identification of filamentous actinomycetes to the genus level using genus-specific 16S-rRNA gene restriction fragment patterns. Int. J. Syst. Evol. Microbiol. 53, 1907-1915 (2003).

14 Wood, S. A., Kirby, B. M., Goodwin, C. M., le Roes, M. \& Meyers, P. R. PCR screening reveals unexpected antibiotic biosynthetic potential in Amycolatopsis sp. strain UM16. J. Appl. Microbiol. 102, 245-253 (2007).

15 Everest, G. J., le Roes-Hill, M., Omorogie, C., Cheung, S.-K., Cook, A. E., Goodwin, C. M. \& Meyers, P. R. Amycolatopsis umgeniensis sp. nov., isolated from soil from the banks of the Umgeni River in South Africa. Antonie van Leeuwenhoek 103, 673-681 (2013).

16 Hacène, H. \& Lefebvre, G. AH17, a new non-polyenic antifungal antibiotic produced by a strain of Spirillospora. Microbios 83, 199-205 (1995).

17 Pfefferle, C., Theobald, U., Gürtler, H. \& Fiedler, H.-P. Improved secondary metabolite production in the genus Streptosporangium by optimization of the fermentation conditions. J. Biotechnol. 80, 135-142 (2000).

18 Betina, V. Bioautography in paper and thin-layer chromatography and its scope in the antibiotic field. J. Chromatogr. 78, 41-51 (1973).

19 Altschul, S. F. et al. Gapped BLAST and PSI-BLAST: a new generation of protein database search programs. Nucleic Acid Res. 25, 3389-3402 (1997).

$20 \mathrm{Kim}, \mathrm{O}$. S. et al. Introducing EzTaxon-e: a prokaryotic 16S rRNA Gene sequence database with phylotypes that represent uncultured species. Int. J. Syst. Evol. Microbiol. 62, 716-721 (2012).
21 Felsenstein, J. Evolutionary trees from DNA sequences: a maximum likelihood approach. J. Mol. Evol. 17, 368-376 (1981).

22 Wayne, L. G. et al. Report of the ad hoc committee on reconciliation of approaches to bacterial systematics. Int. J. Syst. Bacteriol. 37, 463-464 (1987).

23 Everest, G. J. \& Meyers, P. R. Evaluation of the antibiotic biosynthetic potential of the genus Amycolatopsis and description of Amycolatopsis circi sp. nov., Amycolatopsis equina sp. nov. and Amycolatopsis hippodromi sp. nov. J. Appl. Microbiol. 111, 300-311 (2011).

24 Henssen, A., Kothe, H. W. \& Kroppenstedt, R. M. Transfer of Pseudonocardia azurea and 'Pseudonocardia fastidiosa' to the genus Amycolatopsis, with emended species description. Int. J. Syst. Bacteriol. 37, 292-295 (1987).

25 Lee, S. D. Amycolatopsis ultiminotia sp. nov., isolated from rhizosphere soil, and emended description of the genus Amycolatopsis. Int. J. Syst. Evol. Microbiol. 59, 1401-1404 (2009).

26 Tang, S. K. et al. Amycolatopsis halophila sp. nov., a halophilic actinomycete isolated from a salt lake. Int. J. Syst. Evol. Microbiol. 60, 1073-1078 (2010).

27 Lechevalier, M. P. \& Lechevalier, H. Chemical composition as a criterion in the classification of aerobic actinomycetes. Int. J. Syst. Bacteriol. 20, 435-443 (1970).

28 Saitou, N. \& Nei, M. The neighbor-joining method: a new method for reconstructing phylogenetic trees. Mol. Biol. Evol. 4, 406-425 (1987).

29 Takahashi, K. \& Nei, M. Efficiencies of fast algorithms of phylogenetic inference under the criteria of maximum parsimony, minimum evolution, and maximum likelihood when a large number of sequences are used. Mol. Biol. Evol. 17, 1251-1258 (2000)

Supplementary Information accompanies the paper on The Journal of Antibiotics website (http://www.nature.com/ja) 